\title{
Phenotypic Relationships of Common Health Disorders in Dairy Cows to Lactation Persistency Estimated from Daily Milk Weights
}

\author{
J. A. D. R. N. Appuhamy, ${ }^{\star 1}$ B. G. Cassell, ${ }^{*}$ C. D. Dechow, $\dagger$ and J. B. Coleł \\ *Department of Dairy Science, Virginia Polytechnic Institute and State University, Blacksburg 24061 \\ †Department of Dairy and Animal Science, The Pennsylvania State University, University Park 16802 \\ $\ddagger$ Animal Improvement Programs Laboratory, Agricultural Research Service, USDA, Beltsville, MD 20705-2350
}

\section{ABSTRACT}

The objective of this study was to investigate the phenotypic relationship between common health disorders in dairy cows and lactation persistency, uncorrelated with 305-d yield. The relationships with peak yield and days in milk (DIM) at peak were also studied. Daily milk weights and treatment incidence records of 991 Holstein lactations from experimental dairy herds at Virginia Tech and Pennsylvania State University were used. Persistency was calculated as a function of daily yield deviations from standard lactation curves, developed separately for first (FL) and later lactations (LL), and deviations of DIM around reference dates: 128 for FL and 125 for LL. Days in milk at peak and peak yield were computed for each lactation by using Wood's function. The disease traits studied were mastitis (MAST) only during the first $100 \mathrm{~d}$ (MAST1), only after 100 DIM (MAST2), both before and after 100 DIM (MAST12), and at any stage of lactation (MAST1/2), as well as metritis, displaced abomasums, lameness, and metabolic diseases. Each disease was defined as a binary trait, distinguishing between lactations with at least one incidence (1) and lactations with no incidences (0). The relationships of diseases to persistency, DIM at peak, and peak yield were investigated separately for FL and LL for all disease traits except MAST12, which was investigated across parities. The relationships of persistency to probability of the diseases in the same lactation and in the next lactation were examined using odds ratios from a logistic regression model. Metritis and displaced abomasums in FL and LL were associated with significantly higher persistencies. Metabolic diseases and MAST1 in LL were significantly related to higher persistencies. The relationships of MAST2 in both FL and LL, and MAST12 across parities were significant but negative. Cows affected by MAST tended to have less persistent lactations. Most of the

Received February 5, 2007.

Accepted May 10, 2007.

${ }^{1}$ Corresponding author: appuhamy@vt.edu diseases had a significant impact on DIM at peak in LL. In LL, metritis, metabolic diseases, and displaced abomasums tended to significantly delay DIM at peak. Mastitis only after 100 DIM was associated with significantly earlier DIM at peak in LL. Increasing persistency was associated with low MAST2 and MAST1/2 in primiparous cows. None of the diseases studied was significantly related to persistency of the previous lactation.

Key words: cow, health disorder, persistency, phenotypic relationship

\section{INTRODUCTION}

Persistency is defined as the ability of a cow to maintain milk production at a high level after the peak yield (Jamrozik et al., 1997). High persistency is associated with a slow rate of decline in yield after peak production, whereas low persistency is associated with a rapid rate of decline. A cow with greater persistency tends to incur less feed, health, and reproductive costs (Solkner and Fuchs, 1987). Given the same lactational production, persistent lactations are characterized by lower peak yield (Dekkers et al., 1998) reached at later DIM, indicating their association with reduced metabolic stress in early lactation (Ferris et al., 1985).

Antagonistic genetic correlations between milk production and disease traits (Simianer et al., 1991) indicate that increased disease incidence in today's dairy herd (Zwald et al., 2004) is in part a consequence of genetic improvement in milk production. Sick cows are less profitable and sickness can lead to ethical concerns related to animal welfare and consumer interest (Jakobsen et al., 2003). Diseases such as mastitis (MAST), displaced abomasums (DA), ketosis (KET), cystic ovaries (CYST), metritis (MET), and lameness (LAME) can severely affect the profitability of dairy herds through involuntary culling, veterinary treatments, added labor, and lost milk sales (Zwald et al., 2004). Many countries are starting to apply negative selection pressure on disease susceptibility by including disease resistance in breeding goals (Jakobsen et al., 2003). 
Direct selection for disease resistance requires accurate records of disease incidence and severity. Many producers do not record diseases in a manner useful for the purpose. When direct selection for disease resistance is not possible, correlated traits could be useful in indirect selection. Hypothetically, cows having highly persistent lactations are also less liable to diseases because they may have undergone less metabolic stress in the time from calving to peak yield (Dekkers et al., 1998). Thus, genetic changes toward more persistent lactations could be used as a means to decrease disease susceptibility in dairy cows. However, persistency may not be justified at the expense of milk yield, because 305 -d yield tends to be negatively associated with increasing persistency (Dekkers et al., 1998; Togashi and Lin, 2003). Therefore, persistency measures uncorrelated with total yield will allow more efficient selection for total lactation yield and persistency simultaneously (Muir et al., 2004). A phenotypic measure of persistency that is independent of yield can be calculated as a function of a standard lactation curve and a linear regression of a cow's test-day deviations on DIM (Cole and VanRaden, 2006).

The objective of the current study was to examine phenotypic relationships between lactation persistency, independent of 305-d yield, and common health disorders in dairy cows by using daily milk records from experimental dairy farms at Virginia Tech (VT) and Pennsylvania State University (PSU).

\section{MATERIALS AND METHODS}

\section{Data}

Daily milk weights and treatment incidence data of Holstein lactations initiated by calving on or after July 7, 2001, at PSU and July 18, 2004, at VT were used. Lactations of at least 260 DIM were chosen to calculate persistency. The edited data set contained 326 first lactations (FL) and 511 later lactations (LL) from PSU, and $59 \mathrm{FL}$ and $95 \mathrm{LL}$ from VT.

\section{Calculation of Persistency}

VanRaden (1998) reported a method of calculating lactation persistency by multiplying test-day (TD) deviations from a standard lactation curve by corresponding DIM deviations around a reference date, $\mathrm{d}_{0}$ :

$$
\mathrm{p}=\sum_{\mathrm{i}=1}^{\mathrm{n}}\left(\mathrm{Y}_{\mathrm{i}}-\mathrm{S}_{\mathrm{i}}\right) \times\left(\mathrm{d}_{\mathrm{i}}-\mathrm{d}_{0}\right)
$$

where $\mathrm{p}$ is persistency of an individual lactation, $\mathrm{Y}_{\mathrm{i}}$ is the ith TD yield, $\mathrm{S}_{\mathrm{i}}$ is standard yield on the ith TD, $\mathrm{d}_{\mathrm{i}}$

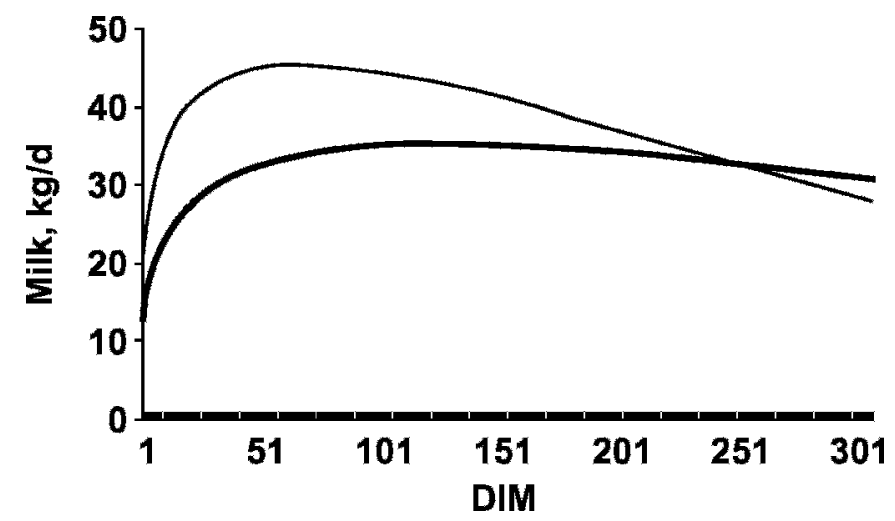

Figure 1. Standard lactations curves for first $(\square)$ and later $(-)$ lactations developed from mean daily milk yields across 2 experimental herds.

is DIM at the ith TD, $\mathrm{d}_{0}$ is DIM at the reference date, and $\mathrm{n}$ is total number of TD yield records used to calculate persistency.

A measure of persistency that is phenotypically uncorrelated with lactation yield may be obtained by defining $\mathrm{d}_{0}$ as a balance point between yields in early and late lactation (Cole and VanRaden, 2006). We used 128 and 125 DIM as the reference dates for FL and LL, respectively, in this study. Because the shape of the lactation curve differs between primiparous and multiparous cows (Jakobsen et al., 2003), 2 standard lactation curves were developed to calculate persistency for FL and LL separately. We fit mean daily milk yields in FL and LL across herds to Wood's function (Wood, 1967) and developed the 2 standard lactation curves shown in Figure 1.

A standardized estimate of persistency ( $(\hat{\mathrm{s}})$ was obtained by subtracting the within-lactation (FL or LL) mean $\left(\mu_{\mathrm{p}}\right)$ and dividing by the within-lactation (FL or LL) phenotypic standard deviation (SD) of calculated persistency:

$$
\hat{\mathrm{s}}=\frac{\mathrm{p}-\mu_{\mathrm{p}}}{\mathrm{SD}} .
$$

Positive values of $\hat{\mathrm{s}}$ indicate increased persistency relative to an average cow, and negative values of $\hat{\mathrm{s}}$ indicate decreased persistency (Cole and VanRaden, 2006).

\section{Defining Disease Traits}

Herd treatment incidence records were used to define disease traits for MAST, MET, KET, milk fever (MF), DA, and LAME. The farm crew at PSU and VT used Dairy Comp 305 (Valley Ag Software, Tulare, CA) and 
PCDART software (DRMS, Raleigh, NC), respectively, to record the treatment events. Both herds are frequently supported by veterinarians and have very thorough recording of health events. Treatment incidences for all udder infections were considered as MAST. We chose to consider MAST under 2 separate stages of lactation, early (before $100 \mathrm{DIM}$ ) and late (after 100 DIM), because MAST in early lactation is likely to have a low correlation with MAST in late lactation (Zwald et al., 2006). Four disease traits were formed with respect to MAST: MAST1, MAST2, MAST12, and MAST1/2, representing MAST only in the early stage, only in the late stage, in both the early and late stages, and in either of the stages, respectively. A disease variable LAME was formed by considering treatment incidences for all causes of limping and abnormal weight bearing, including laminitis, foot rot, hoof abscess, overgrown hoof, and pelvic abscess. Treatments for vaginal discharge or an enlarged uterus diagnosed through veterinary palpation were considered to be MET. Treatment incidences for both KET and MF were pooled into one disease trait, metabolic diseases (METAB). A disease trait for DA was formed by considering the treatment incidences for both left and right abomasal displacements. Each disease trait was defined as a binary trait, distinguishing between cows with at least one reported incidence during the defined period (1) and cows without cases (0; Carlen et al., 2006). In addition to the aforementioned disease traits, we chose 3 other health disorders: retained placenta (RP), CYST, and diarrhea, for inclusion in the statistical models.

\section{Computation of Peak Yield and DIM at Peak}

Although the relationships between persistency and diseases were our main interest, we also examined the relationships of diseases to other lactation curve characteristics, in particular peak yield and DIM at peak, because they would be useful in explaining the relationship between diseases and persistency. Wood's equation was chosen to depict the shape of the lactation curve:

$$
\mathrm{Y}_{\mathrm{t}}=\mathrm{at} \mathrm{t}^{\mathrm{b}} \mathrm{ct}^{\mathrm{ct}}
$$

where $Y_{t}$ is production $(\mathrm{kg})$ on day $\mathrm{t}$, a is a scaling factor estimating production at time zero, $b$ is the rate of ascent to the peak, and $\mathrm{c}$ is the rate of descent after the peak. Two functions using $a, b$, and $c$ were computed: $a[b / c]^{c} e^{-b}$, to calculate peak yield, and $[b / c]$, to estimate DIM at peak (Ferris et al., 1985). Parameter estimates for individual lactations of at least $260 \mathrm{~d}$ in length were obtained through the Gauss-Newton method in the nonlinear procedure (PROC NLIN) in SAS (1999, SAS Inst. Inc., Cary, NC).

\section{Statistical Analysis}

We examined phenotypic relationships between the disease traits and milk yield persistency in 2 directions: first, the relationships of the diseases to persistency, and then, the relationships of persistency to probabilities of disease occurrence.

\section{Relationships of the Diseases to Persistency, Peak Yield, and DIM at Peak}

The following statistical model was used to investigate the relationships of each disease trait to persistency, peak yield, and DIM at peak:

$$
\begin{gathered}
\mathrm{Y}_{\mathrm{ijklmn}}=\mu+\mathrm{H}_{\mathrm{i}}+\mathrm{YR}_{\mathrm{j}}+\mathrm{S}_{\mathrm{k}}+\mathrm{D}_{\mathrm{l}} \\
+\mathrm{O}_{\mathrm{m}}+\beta_{1} \mathrm{DOP}_{\mathrm{ijkl} m n}+\beta_{2} \mathrm{AGE}_{\mathrm{ijklmn}}+\mathrm{e}_{\mathrm{ijk} \mathrm{m} n},
\end{gathered}
$$

where $\mathrm{Y}$ is standardized persistency, peak yield, or DIM at peak; $\mu$ is the overall mean of persistency, peak yield, or DIM at peak; $\mathrm{H}$ is a fixed effect of herd (VT or PSU); YR is a fixed effect of calving year (2001, 2002, 2003, 2004 , or 2005); $\mathrm{S}$ is a fixed effect of calving season [1 (February to April), 2 (May to July), 3 (August to October), or 4 (November to January)]; $D$ is a fixed effect of the presence (1) or absence ( 0 ) of at least one incidence of the main disease of interest; $\mathrm{O}$ is a fixed effect of the presence (1) or absence (0) of at least one incidence of any other disease besides the main disease of interest; $\beta_{1}$ is the regression for days open (DOP); $\beta_{2}$ is the regression for age at calving (AGE) in mo; and $\mathrm{e}_{\mathrm{ijk} k \mathrm{mn}}$ is residual error $\sim \mathrm{N}\left(0, \mathrm{I} \sigma_{\mathrm{e}}{ }^{2}\right)$.

The variable other diseases $(\mathrm{O})$ included RP, CYST, diarrhea, and the other defined disease traits besides the main disease trait of interest (D); that is, the other diseases for MAST1 were MAST2, MAST12, MET, METAB, DA, LAME, RP, CYST, and diarrhea. Days open less than 50 were set to 50 , and days open greater than 250 were set to 250 (Cole and VanRaden, 2006). Primiparous cows differ from multiparous cows because they produce less milk and have different incidence rates for many diseases (Uribe et al., 1995). On the other hand, Jamrozik et al. (1997) suggested that persistency in different lactations can be considered as different traits. We chose to perform separate analyses for FL and LL. However, when disease frequency was $<5 \%$, as for MAST12, data for primiparous and multiparous cows were pooled to avoid the loss of information by empty cells (Uribe et al., 1995). When cows are concomitantly lactating and pregnant, conflicting metabolic demands of gestation and lactation in advanced pregnancy might exacerbate the decline in milk yield in late lactation (Capuco et al., 2003). We included DOP in the statistical model to account for this effect. AGE 
accounted for some parity differences in LL and the negative correlation between persistency and age of heifers at breeding, as reported by Muir et al. (2004).

\section{Relationships of Persistency to Probability of the Diseases}

We examined the relationships between persistency and the likelihood of diseases in the current lactation as well as in the next lactation. We chose not to include MAST1, DA, MET, and METAB in these analyses for the impact of persistency on diseases in the current lactation because expression of these disease traits preceded the expression of persistency.

A linear logistic model was chosen to investigate the effect of persistency on the probability of disease occurrence (Domecq et al., 1997). The probability of observing the disease of interest $\left(Y_{i}=1\right)$ is $\pi_{i}$ and the logit of observing the disease $\left(\mathrm{Y}_{\mathrm{i}}\right)$ is:

$$
\log \left[\pi_{\mathrm{i}} /\left(1-\pi_{\mathrm{i}}\right)\right]=\eta_{\mathrm{i}}
$$

where $\eta_{\mathrm{i}}$ is the linear predictor of the logistic regression model, $\mathrm{Y}_{\mathrm{i}}=1 / 1+\mathrm{e}^{-\eta_{\mathrm{i}}}$.

Because $\pi$ is the probability that $\mathrm{Y}_{\mathrm{i}}=1$, it follows that $1-\pi$ is the probability of $\mathrm{Y}=0$; then, $\pi_{\mathrm{i}} /\left(1-\pi_{\mathrm{i}}\right)$ is the odds ratio of the 2 probabilities. Any factor that increases $\eta_{\mathrm{i}}$ leads to a concomitant increase in $\pi_{\mathrm{i}}$ (Koenig et al., 2005).

We computed several logistic regression models, including indicator variables for class effects such as herd, year of calving, season of calving, presence or absence of other diseases, linear and quadratic effects of persistency, days open, cow age at calving, and interactions among independent variables. We removed the nonsignificant regression coefficients from the initial model based on type 3 chi-squared statistics for likelihood ratios at $P<0.1$ (PROC GENMOD, SAS Inst. Inc.; Montgomery et al., 2001).

The following logistic regression model was chosen:

$$
\eta_{\mathrm{ijkl}}=\beta_{0}+\beta_{1} \mathrm{~S}_{2 \mathrm{i}}+\beta_{2} \mathrm{Y}_{2 \mathrm{j}}+\beta_{3} \mathrm{O}_{1 \mathrm{k}}+\beta_{4} \mathrm{P}_{\mathrm{ijkl}}+\beta_{5} \mathrm{AGE}_{\mathrm{ijkl}},
$$

where $\eta$ is the logit of observing the disease, $\beta_{0}$ is the intercept, $\mathrm{S}_{2}$ is the effect of season 2 (March to May), $\mathrm{Y}_{2}$ is the effect of calving year 2002, $\mathrm{O}$ is the effect of other diseases, $\mathrm{P}$ is the effect of standardized persistency, and AGE is the effect of age at calving.

Relationships of persistency to probability of disease occurrence $(\mathrm{Y}=1)$ were investigated in terms of the corresponding odds ratios. The significance of the odds ratio was determined based on its $95 \%$ confidence interval (CI). A CI including 1 was considered to represent a nonsignificant association between disease incidence
Table 1. Correlations between 305-d yield and persistency calculated for different reference dates $\left(\mathrm{d}_{0}\right)$ in first (FL) and later (LL) lactations

\begin{tabular}{lcc}
\hline $\mathrm{d}_{0}$ & $\mathrm{FL}$ & $\mathrm{LL}$ \\
\hline 130 & -0.063 & -0.124 \\
129 & -0.025 & -0.114 \\
128 & 0.009 & -0.083 \\
127 & 0.043 & -0.056 \\
126 & 0.084 & -0.023 \\
125 & 0.115 & -0.003 \\
124 & 0.125 & 0.032 \\
\hline
\end{tabular}

and persistency. We expressed persistency in SD units. Therefore, the estimated odds ratios in this study describe changes in likelihood that a cow would develop diseases in response to an SD-unit increase in persistency.

The effect of persistency on the probabilities of MAST2, MAST12, MAST1/2, and LAME in the same lactation was examined separately for FL and LL. We used the same logistic model to investigate the effect of persistency on the likelihood of diseases in the next lactation. A total of 181 cows with both first and second lactations were involved in this analysis.

\section{RESULTS}

\section{Calculation of Persistency}

In this study, persistency was calculated by using daily milk records from 305-d lactations. However, lactations that failed to complete 305 DIM but reached at least 260 DIM were also considered for persistency calculation. We made this decision based on the estimated correlations of persistency calculated by using daily yields up to 305 DIM with those calculated by using daily milk yields up to $280,260,240,210$, and 180 DIM. The estimated correlations were $0.95,0.89$, $0.73,0.30$, and 0.00 , respectively. Moreover, lactations that missed daily milk yield records consecutively for $30 \mathrm{~d}$ were excluded from the calculation of persistency.

The notable shape difference between the standard lactation curves (Figure 1) indicated the necessity of 2 values for $\mathrm{d}_{0}$ to calculate persistency for $\mathrm{FL}$ and LL. VanRaden (1998) determined $\mathrm{d}_{0}$ to be 128 for FL Holsteins. Considering 128 as an orientation point, we estimated correlations between $305-d$ milk yield and persistency for $\mathrm{d}_{0}$ values of $124,125,126,127,128,129$, and 130. The correlations are given in Table 1 . We chose 128 and 125 to calculate persistency for FL and LL, respectively, because these days produced phenotypic correlations between persistency and 305-d yield that were nearest to zero.

Persistency ranged from -3.78 to 3.88 in $\mathrm{FL}$ and from -3.03 to 2.88 in LL. The frequency histograms of persis- 


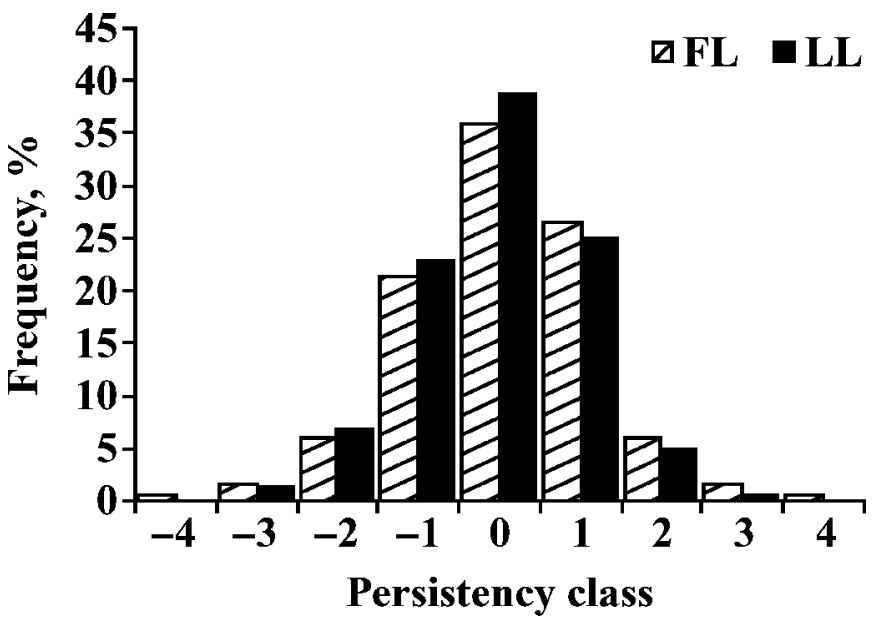

Figure 2. Frequencies of persistency classes in first (FL) and later (LL) lactations. Standardized persistency values were rounded to the nearest integer to form persistency classes.

tency for both FL and LL appear in Figure 2. The persistency values were rounded up to form persistency classes for the histograms (e.g., persistency class 3 included lactations having a persistency of less than 3.5 and greater than 2.5). Distribution of the persistency was virtually normal in both FL and LL. The distributions of mean daily milk yields of FL and LL with high (persistency class 2), average (persistency class 0 ), and low (persistency class -2) persistencies compared with the standard curves are presented in Figure 3A to 3C. High, average, and low persistency classes consisted of 62 , 399, and 50 lactations, respectively. Mean daily yields of lactations with average persistency (Figure 3B) were virtually identical to the standard lactation curves. As expected, highly persistent lactations (Figure $3 \mathrm{~A}$ ) produced less milk at the beginning of lactation and more milk at the end of lactation compared with lactations with the same level of production and average persistency (Cole and VanRaden, 2006). In contrast, lactations of low persistency (Figure 3C) produced more milk in early lactation and less milk during late lactation.

This study used data on 991 Holstein lactations from 2 experimental dairy herds for which daily milk yield was recorded. Larger studies would rely on TD records from commercial herds. We used the method of Cole and VanRaden (2006) to investigate the number of TD yield records (per lactation) required to estimate persistency compared with the use of daily milk weights. The correlations of persistency calculated by using daily milk weights $\left(\mathrm{P}_{305}\right)$ with persistency calculated by using one record per week $\left(\mathrm{P}_{\mathrm{wk}}\right)$, per 2 wk $\left(\mathrm{P}_{2 \mathrm{wk}}\right)$, and per month $\left(\mathrm{P}_{\mathrm{mon}}\right)$ were studied; $\mathrm{P}_{\mathrm{wk}}, \mathrm{P}_{2 \mathrm{wk}}$, and $\mathrm{P}_{\text {mon }}$ involved 44,22 , and 11 yield records, respectively, so that $\mathrm{P}_{\text {mon }}$ was similar to using TD records. The correlations of $\mathrm{P}_{305}$ to $\mathrm{P}_{\mathrm{wk}}, \mathrm{P}_{2 \mathrm{wk}}$, and $\mathrm{P}_{\mathrm{mon}}$, were $0.99,0.97$, and 0.96, respectively, suggesting that TD records can be used to estimate persistency satisfactorily.

\section{Disease Incidence Rates}

Table 2 shows the incidence rates (\%) of health disorders considered in this study. The number of primiparous cows that developed MAST only during early lactation (MAST1) was similar to the number of cows that developed MAST only in late lactation (MAST2), although many more multiparous cows tended to develop MAST2 than MAST1 (17.5 vs. 12.9\%). The frequency of lactations with MAST in both early and late lactation (MAST12) was low (3\%) in FL but considerably higher (10.3\%) in LL. The overall frequency of MAST in early lactation is the summation of the frequencies for MAST1 and MAST12 (e.g., $10.3 \%+7.5 \%=17.8 \%$ for all lactations). Similarly, the overall frequency of MAST in late lactation is the summation of the frequencies of MAST2 and MAST12 (e.g., $12.7 \%+7.5 \%=20.2 \%$ for all lactations). These frequencies suggest that cows in our data were more likely to have MAST in late lactation (after 100 DIM). Mastitis at any time in lactation (MAST1/2) was greater in LL than in FL. Approximately $60 \%$ of the multiparous cows escaped an incidence of MAST. Metritis was more common in FL than in LL (19.1 vs. 9.5\%). The frequencies of DA and LAME in FL and LL were similar. The frequency of METAB increased from $10.6 \%$ in FL to $13.5 \%$ in LL as a consequence of an increasing MF frequency (from $3.0 \%$ to $5.3 \%$ ), whereas the frequency of KET remained fairly constant ( $7.6 \%$ in FL and $8.2 \%$ in LL). More than $85 \%$ of the incidences of METAB, DA, and MET occurred during the first $30 \mathrm{~d}$ after calving (not shown).

\section{Relationships of the Diseases to Persistency}

Table 3 shows the least squares means of persistency in lactations with (1) and without (0) each disease and the significance ( $P$-values) of the diseases on persistency. The relationship of MAST1 to persistency was significant $(P=0.021)$ in LL, showing that multiparous cows that were affected by MAST only during early lactation tended to have more persistent lactations than cows that avoided MAST. Conversely, MAST2 was significantly associated with less persistent FL $(P=0.031)$ and LL $(P=0.002)$. Cows affected with MAST2 had reduced persistency. Lactations in which MAST occurred in both the early and late stages were significantly $(P=0.007)$ less persistent than lactations free of MAST. Similarly, MAST1/2 was associated with significantly $(P=0.023)$ less persistent LL. The LL in 


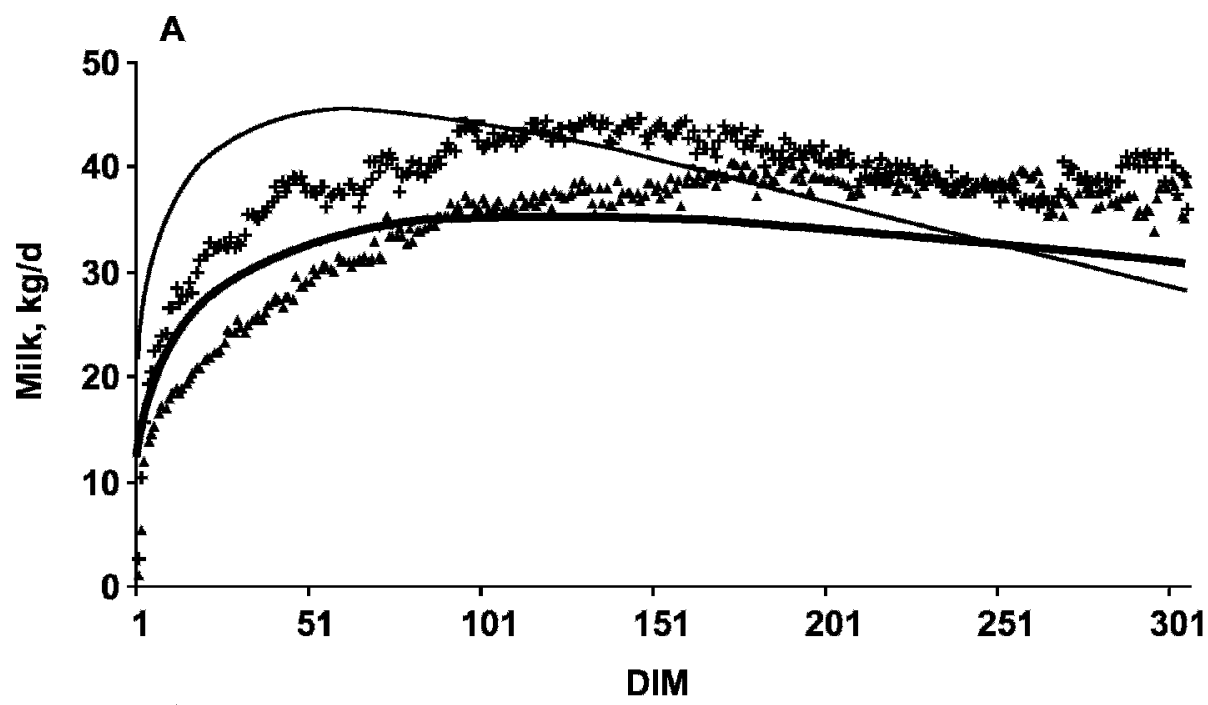

B

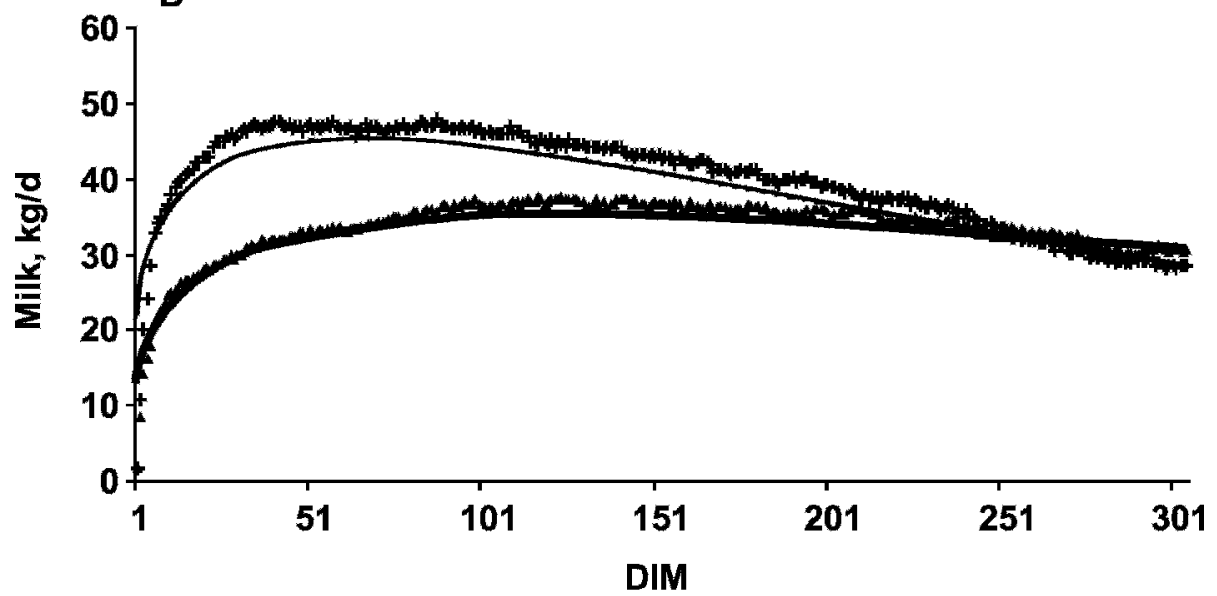

C

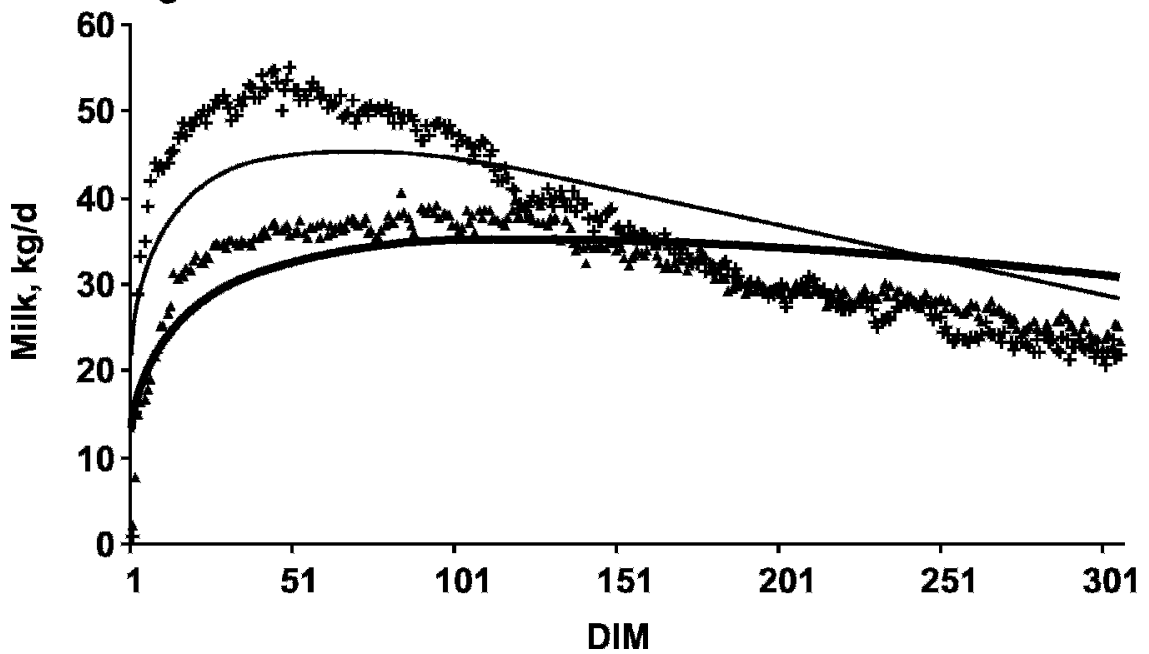

Figure 3. A) Comparison of first lactation (FL; mean daily milk yields of $25 \mathrm{FL}$, $\mathbf{\Delta}$ ) and later lactations (LL; mean daily milk yields of $37 \mathrm{LL},+$ ) of high persistency (standardized persistency values ranging from 1.5 to 2.5) with corresponding standard lactation curves (FL, LL, - ). B) Comparison of FL (mean daily milk yields of $157 \mathrm{FL}, \mathbf{\Delta}$ ) and LL (mean daily milk yields of $242 \mathrm{LL},+$ ) of average persistency (standardized persistency values ranging from -0.5 to 0.5 ) with corresponding standard lactation curves (FL, - ;L, $\longrightarrow$ ). C) Comparison of FL (mean daily milk yields of $20 \mathrm{FL}, \mathbf{\Delta}$ ) and LL (mean daily milk yields of $37 \mathrm{LL},+$ ) of low persistency (standardized persistency values ranging from -2.5 to -1.5 ) with corresponding standard lactation curves (FL, - LL, - 
Table 2. Disease incidence frequencies (\%) in first (FL), later (LL), and all lactations

\begin{tabular}{|c|c|c|c|c|c|c|}
\hline \multirow[b]{2}{*}{ Disease trait $^{1}$} & \multicolumn{2}{|c|}{ FL } & \multicolumn{2}{|c|}{ LL } & \multicolumn{2}{|c|}{ All } \\
\hline & $\mathrm{n}^{2}$ & $\%$ & $\mathrm{n}$ & $\%$ & $\mathrm{n}$ & $\%$ \\
\hline MAST1 & 24 & 6.4 & 78 & 12.9 & 102 & 10.3 \\
\hline MAST2 & 22 & 5.8 & 106 & 17.5 & 128 & 12.7 \\
\hline MAST12 & 12 & 3.0 & 63 & 10.3 & 75 & 7.5 \\
\hline MAST1/2 & 58 & 15.2 & 247 & 40.7 & 305 & 30.5 \\
\hline MET & 73 & 19.1 & 58 & 9.5 & 131 & 13.2 \\
\hline DA & 30 & 7.9 & 45 & 7.4 & 75 & 7.6 \\
\hline MF & 12 & 3.0 & 32 & 5.3 & 44 & 4.4 \\
\hline KET & 29 & 7.6 & 50 & 8.2 & 79 & 8.0 \\
\hline METAB & 41 & 10.6 & 82 & 13.5 & 123 & 12.4 \\
\hline LAME & 94 & 24.0 & 164 & 27.0 & 258 & 26.0 \\
\hline
\end{tabular}

${ }^{1}$ Mastitis only before $100 \mathrm{~d}$ (MAST1), mastitis only after $100 \mathrm{~d}$ (MAST2), mastitis before and after $100 \mathrm{~d}$ (MAST12), mastitis at any time of lactation (MAST1/2), metritis (MET), displaced abomasums (DA), milk fever (MF), ketosis (KET), metabolic diseases (METAB), and lameness (LAME).

${ }^{2}$ Number of lactations that had at least one incidence of the disease.

which METAB (KET + MF) developed were related to significantly $(P=0.0001)$ greater persistency. Displaced abomasums and MET had significantly positive relationships with persistency in both FL $(P<0.0001$ and $P=0.0008$, respectively) and LL $(P<0.0001$ and $P=$ 0.0002 , respectively). In both FL and LL, the differences in persistency between lactations in which LAME developed and lactations that were free of LAME was clearly nonsignificant $(P=0.251$ in $\mathrm{FL}$ and $P=0.263$ in LL).

\section{Relationships of Diseases to Peak Yield and DIM at Peak}

Table 4 presents the relationships between each disease trait and peak yield in FL and LL. In FL, DA was

Table 3. Least squares means (LSM) of persistency and significance $(P$-value) of the each disease trait to persistency in first (FL) and later (LL) lactations

\begin{tabular}{|c|c|c|c|c|c|c|}
\hline \multirow[b]{3}{*}{ Disease trait ${ }^{1}$} & \multicolumn{3}{|c|}{ FL } & \multicolumn{3}{|c|}{ LL } \\
\hline & \multicolumn{2}{|c|}{ LSM } & \multirow[b]{2}{*}{$P$-value } & \multicolumn{2}{|c|}{ LSM } & \multirow[b]{2}{*}{$P$-value } \\
\hline & $0^{2}$ & $1^{3}$ & & 0 & 1 & \\
\hline MAST1 & -0.051 & 0.122 & 0.341 & -0.124 & 0.171 & 0.021 \\
\hline MAST2 & 0.021 & -0.472 & 0.031 & -0.001 & -0.371 & 0.002 \\
\hline MAST1/2 & -0.058 & -0.187 & 0.379 & 0.014 & -0.279 & 0.023 \\
\hline MAST $12^{4}$ & -0.068 & -0.417 & 0.007 & & & \\
\hline METAB & -0.34 & -0.276 & 0.649 & -0.118 & 0.3 & 0.0001 \\
\hline MET & -0.388 & -0.076 & 0.0008 & -0.128 & 0.322 & 0.0002 \\
\hline DA & -0.355 & 0.296 & $<0.0001$ & -0.117 & 0.453 & $<0.0001$ \\
\hline LAME & -0.283 & -0.44 & 0.251 & -0.092 & -0.201 & 0.263 \\
\hline
\end{tabular}

${ }^{1}$ Mastitis only before $100 \mathrm{~d}$ (MAST1), mastitis only after $100 \mathrm{~d}$ (MAST2), mastitis before and after $100 \mathrm{~d}$ (MAST12), mastitis at any time of lactation (MAST1/2), metabolic diseases (METAB), metritis (MET), displaced abomasums (DA), and lameness (LAME).

${ }^{2} \mathrm{LSM}$ for lactations with no incidence of the disease.

${ }^{3} \mathrm{LSM}$ for lactations with at least one incidence for the disease.

${ }^{4}$ Estimated across parities.
Table 4. Least squares means (LSM) of peak yield (kg/d) and significance $(P$-value) of the each disease trait to peak yield in first (FL) and later (LL) lactations

\begin{tabular}{|c|c|c|c|c|c|c|}
\hline \multirow[b]{3}{*}{ Disease trait ${ }^{1}$} & \multicolumn{3}{|c|}{ FL } & \multicolumn{3}{|c|}{ LL } \\
\hline & \multicolumn{2}{|c|}{ LSM } & \multirow[b]{2}{*}{$P$-value } & \multicolumn{2}{|c|}{ LSM } & \multirow[b]{2}{*}{$P$-value } \\
\hline & $0^{2}$ & $1^{3}$ & & 0 & 1 & \\
\hline MAST1 & 33.1 & 32.3 & 0.708 & 38.1 & 36.7 & 0.569 \\
\hline MAST2 & 32.3 & 32.9 & 0.804 & 37 & 41.6 & 0.021 \\
\hline MAST1/2 & 32.2 & 34.7 & 0.071 & 38.6 & 37.6 & 0.551 \\
\hline MAST $12^{4}$ & 36.5 & 33.6 & 0.103 & & & \\
\hline METAB & 32.9 & 30.1 & 0.091 & 38.6 & 37.8 & 0.753 \\
\hline MET & 33.3 & 32.6 & 0.571 & 38.2 & 39.3 & 0.404 \\
\hline DA & 33.5 & 29.3 & 0.026 & 39.5 & 38.3 & 0.324 \\
\hline LAME & 32.9 & 32.7 & 0.881 & 38.6 & 40.7 & 0.202 \\
\hline
\end{tabular}

${ }^{1}$ Mastitis only before $100 \mathrm{~d}$ (MAST1), mastitis only after $100 \mathrm{~d}$ (MAST2), mastitis before and after $100 \mathrm{~d}$ (MAST12), mastitis at any time of lactation (MAST1/2), metabolic diseases (METAB), metritis (MET), displaced abomasums (DA), and lameness (LAME).

${ }^{2} \mathrm{LSM}$ for lactations with no incidence of the disease.

${ }^{3} \mathrm{LSM}$ for lactations with at least one incidence of the disease.

${ }^{4}$ Estimated across parities.

associated with significantly $(P=0.026)$ lower peak yields. In LL, MAST2 was associated with significantly $(P=0.021)$ higher peak yields. Metabolic diseases in both FL and LL $(P=0.004$ and $P=0.003$, respectively $)$, and $\operatorname{MET}(P<0.0001)$ and DA $(P=0.002)$ in LL were significantly associated with longer DIM at peak (Table 5). Mastitis both before and after 100 DIM (MAST12) significantly $(P=0.004)$ reduced DIM at peak across parities, and MAST1/2 was associated with significantly $(P=0.003)$ early peak yields in multiparous cows. The correlations of persistency to peak yield and DIM at peak were -0.04 and 0.70 , respectively, in FL and

Table 5. Least squares means (LSM) of DIM at peak and significance $(P$-value) of each disease trait to DIM at peak in first $(\mathrm{FL})$ and later (LL) lactations

\begin{tabular}{|c|c|c|c|c|c|c|}
\hline \multirow[b]{3}{*}{ Disease trait $^{1}$} & \multicolumn{3}{|c|}{ FL } & \multicolumn{3}{|c|}{ LL } \\
\hline & \multicolumn{2}{|c|}{ LSM } & \multirow[b]{2}{*}{$P$-value } & \multicolumn{2}{|c|}{ LSM } & \multirow[b]{2}{*}{$P$-value } \\
\hline & $0^{2}$ & $1^{3}$ & & 0 & 1 & \\
\hline MAST1 & 138 & 147 & 0.594 & 68 & 72 & 0.420 \\
\hline MAST2 & 141 & 107 & 0.081 & 73 & 68 & 0.246 \\
\hline MAST1/2 & 140 & 131 & 0.427 & 77 & 63 & 0.003 \\
\hline MAST $12^{4}$ & 106 & 82 & 0.004 & & & \\
\hline METAB & 137 & 167 & 0.004 & 69 & 85 & 0.003 \\
\hline MET & 136 & 151 & 0.125 & 67 & 92 & $<0.0001$ \\
\hline DA & 139 & 152 & 0.327 & 69 & 96 & 0.002 \\
\hline LAME & 108 & 110 & 0.599 & 64 & 66 & 0.533 \\
\hline
\end{tabular}

${ }^{1}$ Mastitis only before $100 \mathrm{~d}$ (MAST1), mastitis only after $100 \mathrm{~d}$ (MAST2), mastitis before and after $100 \mathrm{~d}$ (MAST12), mastitis at any time of lactation (MAST1/2), metabolic diseases (METAB), metritis (MET), displaced abomasums (DA), and lameness (LAME).

${ }^{2} \mathrm{LSM}$ for lactations with no incidence of the disease.

${ }^{3} \mathrm{LSM}$ for lactations with at least one incidence of the disease.

${ }^{4}$ Estimated across parities. 
Table 6. Means and phenotypic correlations (r) for 305-d yield, peak yield, DIM at peak, and persistency in first (FL) and later (LL) lactations

\begin{tabular}{|c|c|c|c|c|c|c|}
\hline \multirow[b]{2}{*}{ Trait } & \multicolumn{2}{|c|}{ Mean } & \multicolumn{4}{|c|}{$\mathrm{r}^{1}$} \\
\hline & FL & LL & $\begin{array}{l}\text { 305-d } \\
\text { yield }\end{array}$ & $\begin{array}{l}\text { Peak } \\
\text { yield }\end{array}$ & $\begin{array}{c}\text { DIM } \\
\text { at peak }\end{array}$ & Persistency \\
\hline 305-d yield, kg & 10,257 & 11,889 & & 0.96 & 0.23 & 0.009 \\
\hline Peak yield, kg/d & 37.2 & 47.2 & 0.91 & & 0.14 & -0.04 \\
\hline DIM at peak & 115 & 67 & 0.01 & -0.01 & & 0.70 \\
\hline Persistency & 0 & 0 & -0.003 & -0.13 & 0.82 & \\
\hline
\end{tabular}

${ }^{1} \mathrm{FL}$ (above diagonal) and LL (below diagonal).

-0.13 and 0.82 , respectively, in LL (Table 6). Higher persistency was associated with low peak yield and later DIM at peak. The phenotypic relationship between persistency and DIM at peak was much stronger, as reported by Ferris et al. (1985).

Regardless of the diseases analyzed, calving season had a significant $(P=0.0006)$ impact on persistency in both FL and LL. Cows that calved from August to October (season 3) had the greatest persistency, followed by cows that calved from May to July (season 2), from February to March (season 1), and from November to January (season 4). Calving season also significantly $(P=0.0004)$ affected DIM at peak in FL. The highest DIM at peak were found among primiparous cows that calved in season 3 , followed by those that calved in seasons 1,2 , and 4 .

\section{Relationships of Persistency to the Probability of Disease Occurrence}

The odds ratios and associated CI for the relationships between persistency and likelihood of each disease in the current lactation are presented in Table 7. The odds ratio for MAST2 in FL (0.46) indicates that each SD unit increase in persistency reduced the risk of MAST2 by more than half. In FL, the probability of MAST1/2 decreased by 0.41 for each SD-unit increase in persistency. The odds ratios indicated that increased persistency was associated with less mastitis (MAST2,

Table 7. Odds ratios and $95 \%$ confidence intervals (CI) for the relationships of persistency in first (FL) and later (LL) lactations to disease probabilities in the same lactation

\begin{tabular}{lccccc}
\hline & \multicolumn{2}{c}{ FL } & & \multicolumn{2}{c}{ LL } \\
\cline { 2 - 3 } \cline { 5 - 6 } Disease $^{1}$ & Odds ratio & CI & & Odds ratio & CI \\
\hline MAST2 & 0.46 & $0.30-0.72$ & & 0.77 & $0.61-0.97$ \\
MAST12 & 0.87 & $0.48-1.60$ & & 0.70 & $0.53-0.95$ \\
MAST1/2 & 0.59 & $0.42-0.83$ & & 0.82 & $0.65-1.03$ \\
LAME & 0.95 & $0.74-1.24$ & & 0.94 & $0.77-1.15$ \\
\hline
\end{tabular}

${ }^{1}$ Mastitis only after $100 \mathrm{~d}$ (MAST2), mastitis before and after $100 \mathrm{~d}$ (MAST12), mastitis at any time of lactation (MAST1/2), and lameness (LAME).
MAST12, and MAST1/2) in LL. Higher persistency was associated with very little change in the probability of LAME in both FL and LL. Odds ratios and corresponding CI (Table 8) indicated that persistency in the previous lactation had no significant impact on the probability of any disease in the next lactation.

\section{DISCUSSION}

\section{Disease Frequencies}

Comparison of disease incidence frequencies across different studies is difficult, because procedures for diagnosis, data-recording methods, and disease trait definitions vary from study to study (Harder et al., 2006). Zwald et al. (2004) reported mean lactational incidence rates (across parities) of $3,10,20,10$, and $21 \%$ for DA, KET, MAST, LAME, and MET, respectively. The corresponding disease frequencies estimated by Wilson et al. (2004) were 2.2, 12.3, 19.6, 33.0, and $13.9 \%$, respectively, for FL and 2.9, 12.6, 28.8, 31.0, and $4.4 \%$, respectively, for LL. Wilson et al. (2004) studied diseases in 2 large commercial Holstein dairy herds in New York state that were provided with standard procedures for diagnosis. The frequency estimates by Zwald et al. (2004) were based on producer-recorded health data from commercial Holstein herds located in

Table 8. Odds ratios and associated $95 \%$ confidence intervals (CI) for the relationships of persistency to probabilities of diseases in the next lactation

\begin{tabular}{|c|c|c|}
\hline Disease trait $^{1}$ & Odds ratio & CI \\
\hline MAST1 & 1.13 & $0.96-1.33$ \\
\hline MAST2 & 0.96 & $0.84-1.09$ \\
\hline MAST12 & 1.17 & 0.99-1.39 \\
\hline MAST1/2 & 1.08 & $0.96-1.21$ \\
\hline METAB & 1.13 & $0.98-1.32$ \\
\hline MET & 1.04 & $0.91-1.19$ \\
\hline DA & 1.00 & $0.88-1.16$ \\
\hline LAME & 0.87 & $0.78-1.01$ \\
\hline
\end{tabular}

${ }^{1}$ Mastitis only before $100 \mathrm{~d}$ (MAST1), mastitis only after $100 \mathrm{~d}$ (MAST2), mastitis before and after $100 \mathrm{~d}$ (MAST12), mastitis at any time of lactation (MAST1/2), metabolic diseases (METAB), metritis (MET), displaced abomasums (DA), and lameness (LAME). 


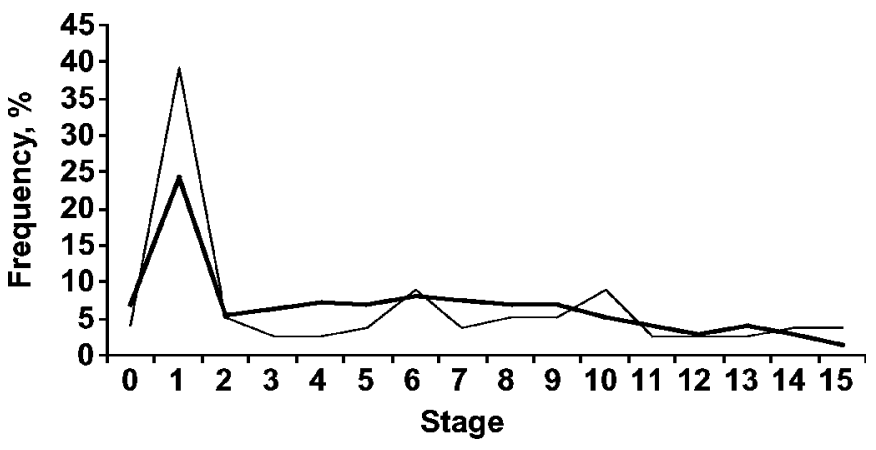

Figure 4. Distribution of total treatment incidence of mastitis over $305 \mathrm{~d}$ in first (FL) and later (LL) lactations. Stage $0=$ day of calving; stages 1 to 15 = each of 20 -d periods; frequency = frequency distribution of total mastitis incidence in FL $(\longrightarrow)$ and LL (-).

the Northeast, Southeast, South, Midwest, and Great Plains areas of the United States. The frequencies for MAST12, LAME, and DA in this study were considerably greater than those for commercial herds reported by Zwald et al. (2004). Relatively more intensive health management practices in the experimental dairy herds (VT and PSU) might have inflated the incidence rates of these diseases. However, the trends of disease frequencies from FL to LL were similar to many studies. The disease frequencies of MAST1, MAST2, MAST12, and MAST1/2 increased from FL to LLs, whereas that of MET decreased. The frequencies of KET, LAME, and DA were relatively unchanged in FL and LL.

We defined disease frequency as a percentage of total lactations (FL, LL, or all) that had at least one incidence of the disease of interest. Therefore, the disease frequencies in this study, as presented in Table 2, can be considered as minimum lactational incidence rates for diseases such as MAST, because multiple cases can occur in the whole lactation or in a defined period of lactation. These incidence rates indicate that multiparous cows tended to develop MAST more frequently in late lactation than in early lactation. However, when the distribution of total MAST incidences (Figure 4) was concerned, the frequency of MAST was greater in early lactation than in late lactation (Wilson et al., 2004; Hinrichs et al., 2005) of multiparous cows. Defining diseases such as MAST as a binary variable sacrifices some information contained in repeated incidences (Carlén et al., 2006).

\section{Relationships of the Diseases to Persistency, Peak Yield, and DIM at Peak}

Overall, the relationships of MAST1, MAST2, and MAST1/2 to persistency appeared to be more substantial in multiparous cows than in primiparous cows. The weak positive association of MAST1 in primiparous cows was much stronger in multiparous cows. Moreover, the negative relationship of MAST2 in primiparous cows became more significant in multiparous cows. The corresponding disease frequencies (Table 2) indicate that multiparous cows tended to develop MAST more frequently than primiparous cows. Estimated correlations between persistency and DIM at peak $(0.70$ in FL and 0.82 in $\mathrm{LL}$ ) reflect the view that lactations associated with delayed peak yield are likely to be more persistent (Muir et al., 2004). The positive relationships of MAST1 to persistency suggest that health disorders in early lactation may suppress an increasing rate of milk secretion and prevent milk yield from reaching its maximum level soon after calving. This may allow cows to utilize their energy reserves slowly and efficiently while maintaining their production without developing a rapid decline after peak (Ferris et al., 1985). On the other hand, MAST2 did not control peak yield as did MAST1, METAB, MET, and DA. However, we observed an association between MAST2 and early DIM at peak, which was significant in multiparous cows. Early peak production results in a severe negative energy balance that may down-regulate the energetic process maintaining the general health status of cows (Collard et al., 2000). Therefore, one can argue that MAST tends to occur in lactations associated with early DIM because high yield creates a favorable environment (i.e., immunosuppressed) for bacteria to infect. Nonetheless, MAST2 had a significant negative relationship with persistency in both FL and LL. Capuco et al. (2003) noted that increased milk yield during early lactation appeared mainly due to increased secretory activity per cell, but the decline in milk yield after peak was solely associated with decreased cell numbers due to apoptosis. These authors also noted that MAST could enhance mammary cell apoptosis. Therefore the impact of MAST on persistency can be negative when it occurs after the peak. The significant negative relationship between MAST12 and persistency indicates that when MAST occurs in both the early and late stages of lactation, the effect of later occurrence is more likely to be stronger.

The positive association of METAB with persistency tended to be more substantial in multiparous cows. The incidence rate of METAB was greater in multiparous cows than in primiparous cows (13 vs. 10\%). The significant positive relationships of the other periparturiant diseases (DA and MET) indicate that illness in early lactation tends to produce more persistent lactations. In connection with this contention, Muir et al. (2004) reported that Canadian Holstein heifers that had a difficult first calving had more persistent FL, whereas Harder et al. (2006) reported that metabolic diseases 
(KET, MF, and DA) appeared to increase persistency in German Holstein cows. We observed that cows experiencing periparturiant diseases tended to have low peak yields and late DIM to peak. The relationship between DIM at peak and persistency was much stronger than the relationship between persistency and peak yield. Periparturiant diseases appear to affect persistency more strongly by delaying DIM at peak than by reducing peak yield.

Table 4 shows that the majority of disease traits were not strongly related to peak yield. The antagonistic relationship between disease resistance and total production (Simianer et al., 1991) suggests that high-producing cows are more susceptible to health disorders than low-producing cows. Wilson et al. (2004) noted that even after high-producing sick animals contracted diseases, their milk yield could be better than or similar to that of their healthy, low-producing herdmates. In this context, the stronger correlation between peak yield and 305-d production (0.91 in FL and 0.96 in LL in our data) shows that the difference in peak yields between sick and healthy cows could also be nonsignificant. However, we forced persistency to be uncorrelated with 305-d yield. Thus, the phenotypic relationships between persistency and diseases in this study are independent of the antagonistic association between level of production and diseases. The phenotypic relationships of LAME to peak yield, DIM at peak, and persistency seem to be very weak. But from a genetic relationships view point, Harder et al. (2006) found LAME to be much more strongly correlated with milk yield persistency.

\section{Relationships of Persistency to the Probability of Disease Occurrence}

Overall, the association of persistency with the probability of MAST is more pronounced in primiparous cows than multiparous cows. Increasing persistency was associated with a decreased likelihood of MAST2 in the current lactation of primiparous cows. Furthermore, primiparous cows with more persistent lactations were less likely to develop MAST in any stage of the lactation (MAST1/2). We examined the relationships between persistency in the previous lactation and the likelihood of diseases in the present lactation. None of the disease traits had strong associations with persistency in the previous lactation. Nevertheless, the majority of disease traits had significant relationships with persistency in the same lactation. We conclude that many common health traits in dairy cows tend to significantly affect persistency. On the other hand, the occurrence of many diseases does not appear to be affected by changes in persistency. The relationship between LAME and persistency was not strong, regardless of whether we treated it as a causative factor or as a result of persistency. The frequency of LAME in these data was more than twice that of some estimates in the literature (i.e., Zwald et al., 2004). Perhaps a more specific definition of LAME would produce different results. Furthermore, we defined disease traits by considering only the presence or absence of at least one incidence of the disorders in the whole lactation or in a particular stage of lactation. Hence, the estimated relationships in this study do not satisfactorily account for the severity and repeated incidence of diseases such as MAST and LAME (Domecq et al., 1997).

\section{CONCLUSIONS}

Mastitis in early lactation was significantly associated with increased persistency in multiparous cows. Both primiparous and multiparous cows that developed MAST in late lactation had significantly less persistent lactations. The relationship of MAST in both early and late lactation to persistency was significant but negative across parities. Irrespective of the time of occurrence, MAST tended to reduce persistency. Postpartum METAB, DA, and MET were strongly related to persistency and tended to force the peak yield to occur at later DIM.

More persistent primiparous cows tended to develop MAST less frequently in the late stage of lactation. Persistency had no significant association with the likelihood of diseases in the subsequent lactation. The results of this study suggest that diseases tend to significantly affect lactation persistency rather than persistency affecting disease occurrence. The relationships in this study are phenotypic. Inclusion of persistency in the breeding goal to improve disease resistance needs to be based on genetic relationships.

\section{ACKNOWLEDGMENT}

The authors are grateful for the financial support provided by the Animal Improvement Programs Laboratory, USDA.

\section{REFERENCES}

Capuco, A. V., S. E. Ellis, S. A. Hale, R. A. Edman, X. Zhao, and M. J. Paape. 2003. Lactation persistency, insights from mammary cell proliferation studies. J. Anim. Sci. 81:18-31.

Carlén, E., U. Emanuelson, and E. Strandberg. 2006. Genetic evaluation of mastitis in dairy cattle using linear models, threshold models, and survival analysis: A simulation study. J. Dairy Sci. 89:4049-4057.

Cole, J. B., and P. M. VanRaden. 2006. Genetic evaluation and best prediction of lactation persistency. J. Dairy Sci. 89:2722-2728.

Collard, B. L., P. J. Boettcher, J. C. Dekkers, D. Petitcler, and L. R. Schaeffer. 2000. Relationships between energy balance and health traits of dairy cattle in early lactation. J. Dairy Sci. 83:2683-2690. 
Dekkers, J. C. M., J. H. Ten Hag, and A. Weersink. 1998. Economic aspects of persistency of lactation in dairy cattle. Livest. Prod. Sci. 53:237-252.

Domecq, J. J., A. L. Skidmore, J. W. Lloyd, and J. B. Kaneene. 1997. Relationships between body condition scores and conception at first artificial insemination in a large dairy herd of high-yielding Holstein cows. J. Dairy Sci. 80:113-120.

Ferris, T. A., I. L. Mao, and C. R. Anderson. 1985. Selection for lactation curve and milk yield in cattle. J. Dairy Sci. 68:14381448.

Harder, B., J. Bennewitz, D. Hinrichs, and E. Kalm. 2006. Genetic parameters for health traits and their relationship to different persistency traits in German Holstein dairy cattle. J. Dairy Sci. 89:3202-3212.

Hinrichs, D., E. Stamer, W. Junge, and E. Kalm. 2005. Genetic analysis of mastitis data using animal threshold models and genetic correlation with production traits. J. Dairy Sci. 88:2260-2268.

Jakobsen, J. H., R. Rekaya, J. Jensen, D. A. Sorensen, P. Madesen, D. Gianola, L. G. Christensen, and J. Pedersen. 2003. Bayesian estimates of covariance components between lactation curve parameters and disease liability in Danish Holstein cows. J. Dairy Sci. 86:3000-3007.

Jamrozik, J., L. R. Schaeffer, and J. C. M. Dekkers. 1997. Genetic evaluation of dairy cattle using test day yields and random regression model. J. Dairy Sci. 80:1217-1226.

Koenig, S., A. R. Sharifi, H. Wentrot, D. Landmann, M. Eise, and H. Simianer. 2005. Genetic parameters of claw and foot disorders estimated with logistic model. J. Dairy Sci. 88:3316-3325.

Montgomery, D. C., E. A. Peck, and G. G. Vining. 2001. Introduction to Linear Regression Analysis. John Wiley and Sons, New York, NY.
Muir, B. L., J. Fatehi, and L. R. Schaeffer. 2004. Genetic relationships between persistency and reproductive performances in first-lactation Canadian Holsteins. J. Dairy Sci. 87:3029-3037.

Simianer, H., H. Solbu, and L. R. Schaeffer. 1991. Estimated genetic correlations between diseases and yield traits in dairy cattle. J. Dairy Sci. 74:4358-4365.

Solkner, J., and W. Fuchs. 1987. A comparison of different measures of persistency with special respect to variation of test-day milk yields. Livest. Prod. Sci. 16:305-319.

Togashi, K., and C. Y. Lin. 2003. Modifying the lactation curve to improve lactation milk and persistency. J. Dairy Sci. 86:14871493.

Uribe, H. A., B. W. Kennedy, S. W. Martin, and D. F. Ketton. 1995. Genetic parameters for common health disorders of Holstein cows. J. Dairy Sci. 78:421-430.

VanRaden, P. M. 1998. Best prediction of lactation yield and persistency. Proc. 6th World Congr. Genet. Appl. Livest. Prod. (Armidale, Australia) 23:347-350.

Wilson, D. J., R. N. Gonzalez, J. Hertl, H. F. Schulte, G. J. Bennett, Y. H. Schukken, and Y. T. Grohn. 2004. Effect of clinical mastitis on the lactation curve: A mixed model estimation using daily milk weight. J. Dairy Sci. 87:2073-2084.

Wood, P. D. R. 1967. Algebraic model of the lactation curve in cattle. Nature 216:164-165.

Zwald, N. R., K. A. Weigel, Y. M. Chang, R. D. Welper, and J. S. Clay. 2004. Genetic selection for health traits using producerrecorded data. I. Incidence rates, heritability estimates, and sire breeding values. J. Dairy Sci. 87:4287-4294.

Zwald, N. R., K. A. Weigel, Y. M. Chang, R. D. Welper, and J. S. Clay. 2006. Genetic analysis of clinical mastitis data from onfarm management software using threshold models. J. Dairy Sci. $89: 330-336$ 